\title{
Pattern of drug utilization and factors influencing long term blood sugar control among diabetics in a tertiary care hospital- an observational study
}

\author{
Raghu Prasada M. S. ${ }^{1 *}$, Deepa Patil ${ }^{1}$, Vishwanath B. M. ${ }^{2}$, Shankar A. S. ${ }^{3}$, \\ Umakant N. Patil ${ }^{1}$, Sharankumar Holyachi ${ }^{4}$
}

${ }^{1}$ Department of Pharmacology, SS Institute of Medical Sciences and Research Institute,

Davangere, Karnataka, India

${ }^{2}$ Department of Medicine, JJM

Medical College, Davangere,

Karnataka, India

${ }^{3}$ Micro Labs, Bangalore,

Karnataka, India

${ }^{4}$ Department of Community

Medicine, Koppal Institute of

Medical Sciences, Koppal,

Karnataka, India

Received: 02 March 2017

Accepted: 01 April 2017

*Correspondence to:

Dr. Raghu Prasada M. S.,

Email:

raghuprasada@gmail.com

Copyright: (C) the author(s), publisher and licensee Medip Academy. This is an openaccess article distributed under the terms of the Creative Commons Attribution NonCommercial License, which permits unrestricted noncommercial use, distribution, and reproduction in any medium, provided the original work is properly cited.

\begin{abstract}
Background: To study the Pattern of drug prescribing, utilization, analyse effectives of different therapies and factors influencing medication failure and adherence to treatment among diabetics.

Methods: The clinical study was conducted in JJM Medical College and Karuna Trust, Davangere, Karnataka. The patients with diabetes as diagnosed by consultant physician were observed for the pattern of blood glucose control. The fasting blood glucose of the patients were recorded at the end of 1 st month, 6th month and $12^{\text {th }}$ month of their treatment period. The study period was from June 2012 till August 2014. The study was conducted after institutional ethical clearance and informed consent was taken from all the patients. The pattern of drugs prescribed for the patients were also analysed. The pattern of control among patients with co morbidities were also analysed using paired sample $t$ test.

Results: The results showed that the prescribed drugs were able to control the blood glucose levels of the patients. The percentage of patients with FBS in controlled, mild to moderate control and uncontrolled group were $21 \%, 33.3 \%$ and $45.5 \%$ in early treatment period and $36 \%, 40.9 \%$, and $22.7 \%$ after one year treatment period (Significant $\mathrm{p}$ value). The pattern of drug utilization showed that the most commonly used drugs were the combination of pioglitazone+glimipride+metformin $(19 \%)$, combination of glibenclamide+ metformin (18\%), only insulin (9\%), combination of glimipride+metformin $(8 \%)$ and combination of gliclazide+metformin (5\%).

Conclusions: The results show that the intervention by the consultant physician was successful in controlling the blood sugar levels and the reasons for failure of treatment and adherence to treatment were helpful for further treatment of patients. Further such studies in a larger sample will help the consultants in their treatment methods.
\end{abstract}

Keywords: Diabetes, Drug utilization, Observational study, Prescription pattern

\section{INTRODUCTION}

Diabetes mellitus is a metabolic disorder of multiple etiologies, characterized by chronic hyperglycemia. ${ }^{1}$ It has emerged as a major health problem in India. ${ }^{2}$ It is fast gaining the status of potential epidemic in India with more than 62 million diabetic individuals currently diagnosed with the disease. This number is expected to increase to 79.4 million by $2030 .^{3}$ The crude prevalence rate in urban areas of India is apparently $9 \%$ and in rural 
areas approximately $3 \%$ of the total population. Global prevalence of diabetes in age groups 20-79 years in 2011 was $8.3 \%$ and projected rise $9.9 \%$ in 2030 . As per the International Federation of Diabetes number of people with diabetes till 2011 were 366 million and projected to rise 552 million in 2030 with maximum increase in India. ${ }^{3},{ }^{4}$ Drug utilization has been defined as the marketing, distribution, prescription, and use of drugs in a society, with emphasis on the resulting medical and social consequences. DUS is an essential part of pharmacoepidemiology. The principal aim of drug utilization studies (DUS) is to facilitate the rational use of drugs in population, also describes the nature and drug exposure, and may also help to identify non-adherence problems. $^{2}$ Non adherence and poor follow ups are the main factors responsible for poor glycemic control with high risk of development of long term micro and macrovascular complications. ${ }^{5}$ Hence the present study was undertaken with aim of providing relevant and useful feedback to physicians. By doing these prescribing pattern studies we could provide feedback to prescribers and assures quality medical care. The current study also attempts to analyze the current prescription patterns of drugs used in the treatment of both type 1 and type 2 diabetes mellitus patients.

\section{METHODS}

The clinical study was conducted in JJM Medical College and Karuna trust, Davangere, Karnataka. The patients with Diabetes as diagnosed by consultant physician were observed for the pattern of blood glucose control. The fasting blood glucose of the patients were recorded at the end of $1^{\text {st }}$ month, $6^{\text {th }}$ month and $12^{\text {th }}$ month of their treatment period. The study period was from June 2012 till August 2014. The study was conducted after institutional ethical clearance and informed consent was taken from all the patients. Blood sugar level of less than $130 \mathrm{mg} \%, 130-200 \mathrm{mg} \%$ and above $200 \mathrm{mg} \%$ were grouped as level of control 1, 2 and 3 respectively. The FBS1 FBS2 and FBS3 are fasting blood sugar levels at the end of first month, at the end of 6 months and at the end of 12 months. The reasons for uncontrolled were collected based on the questionnaire answered by the patients. The pattern of drugs prescribed for the patients and pattern of control among patients with co morbidities were analyzed using paired sample t test.

\section{Inclusion criteria}

- Patients of either sex, irrespective of their socioeconomic status background.

- Patient with newly diagnosed Type 1 and Type 2 diabetes as diagnosed by physician.

- Patient with glycosylated haemoglobin of more than $6.5 \%$.

\section{Exclusion criteria}

- Patients with gestational diabetes
- Patients with diabetic complications

- Patients who are not willing to give consent

\section{RESULTS}

The results showed that the prescribed drugs were able to control the blood glucose levels of the patients. The percentage of patients with FBS in controlled, mild to moderate control and uncontrolled group were $21 \%$, $33.3 \%$ and $45.5 \%$ in early treatment period and $36 \%$, $40.9 \%$, and $22.7 \%$ after one year treatment period. (Significant $\mathrm{p}$ value). The pattern of drug utilization showed that the most commonly used drugs were the combination of pioglitazone+glimipride+metformin (19\%), combination of glibenclamide+metformin (18\%), only insulin (9\%), combination of glimipride+metformin $(8 \%)$ and combination of gliclazide+metformin $(5 \%)$.

Table 1: Medications given.

\begin{tabular}{|lll|}
\hline & Frequency & $\%$ \\
\hline Glibenclamide+metformin & 18 & 27.3 \\
\hline Gliclazide+metformin & 5 & 7.6 \\
\hline Glipizide+metformin & 4 & 6.1 \\
\hline Pioglitazone & 2 & 3.0 \\
\hline Glimipride+metformin & 8 & 12.1 \\
\hline $\begin{array}{l}\text { Pioglitazone+glimipride+ } \\
\text { metformin }\end{array}$ & 19 & 28.8 \\
\hline Only insulin & 9 & 13.6 \\
\hline Pioglitazone+metformin & 1 & 1.5 \\
\hline Total & 66 & 100.0 \\
\hline
\end{tabular}

Table 2: Reasons for uncontrolled FBS levels.

\begin{tabular}{|ll|}
\hline Reasons & Patients \\
\hline Controlled & 17 \\
\hline Unknown reasons & 22 \\
\hline Followup irregularity & 8 \\
\hline Non-compliance due to side-effects & 4 \\
\hline $\begin{array}{l}\text { Illitracy, medication unawareness, lack } \\
\text { of diet control }\end{array}$ & 6 \\
\hline Polypharmacy, comorbidities & 8 \\
\hline Habits-tobacco chewing, smoking & 1 \\
\hline Total & 66 \\
\hline
\end{tabular}

Table 3 shows the cross tabulation of blood sugar levels at the end of one month (FBS1) and at the end of 6 months (FBS3). At the end of first month, the number of patients with the blood sugar levels <130mg, 130-200mg, >200mg were 13, 23 and 30 patients. At the end of 6 months blood sugar levels categories had 18, 30 and 18 patients in their respective categories. Patients with more than $200 \mathrm{mg}$ decreased from 30 to 18 after 6 months of treatment.

In present study, most number of patients (28.8\%) received a combination of pioglitazone+metformin+glimepiride followed by a combination of glibenclamide+metformin $(27.3 \%)$ and only insulin was given to $13.6 \%$ patients which included both Type 1 and Type 2 diabetes mellitus. The next group 
was glimepiride+metformin combination with $12 \%$ of patient (Table 1). At the beginning of the treatment we had 30 patients $(45 \%)$ in uncontrolled group, 23 patients $(34.8 \%)$ in controlled group and at the end of 1 year treatment we had only 18 patients $(27 \%)$ in the uncontrolled group (Table 2). On applying Chi square test p value was significant $(\mathrm{P}<0.01)$ (Table 3$)$. On comparing the means of FBS1 (fast blood sugar level at the end of one month) and FBS3 (Fasting blood Sugar Level at the end of 12 month), mean for FBS1 was 206 and for FBS3 was 171.6 and mean difference was 33.42 and $P$ value was significant $(\mathrm{P} \leq 0.01)$.

Table 3: Level of control $1 *$ level of control 2 cross tabulation.

\begin{tabular}{|llll|l|}
\hline $\begin{array}{l}\text { Level of control (FBS1) } \\
\text { month }\end{array}$ & \multicolumn{1}{l}{ Level of control (FBS2) $\mathbf{6}$ months } & & Total \\
\hline $1.00(<130 \mathrm{mg})$ & $\mathbf{1 . 0 0}$ & $\mathbf{2 . 0 0}$ & $\mathbf{3 . 0 0}$ & No. $(\boldsymbol{\%})$ \\
\hline $2.00(130-200 \mathrm{mg})$ & $7(53.8)$ & $6(46.2)$ & $0(0.0)$ & $13(100.0)$ \\
\hline $3.00(>200 \mathrm{mg})$ & $7(30.4)$ & $13(56.5)$ & $3(13.0)$ & $23(100.0)$ \\
\hline Total & $4(13.3)$ & $11(36.7)$ & $15(50.0)$ & $30(100.0)$ \\
\hline
\end{tabular}

FBS1-at one month of treatment, FBS2-at end of 6 months of treatment, Level of control $1.00<130 \mathrm{mg} \%, 2.00-130-200 \mathrm{mg} \%$, $3>200 \mathrm{mg} \%$

Table 4: Paired sample T test comparing means.

\begin{tabular}{|c|c|c|c|c|c|c|c|c|}
\hline & & Mean & $\mathbf{N}$ & Std. deviation & Mean difference & $\mathbf{t}$ & df & P value \\
\hline \multirow{2}{*}{ Pair 1} & FBS1 & 206.6061 & 66 & 95.72282 & \multirow{2}{*}{33.42424} & \multirow{2}{*}{3.124} & \multirow{2}{*}{65} & \multirow{2}{*}{.003} \\
\hline & FBS3 & 171.6667 & 66 & 60.57477 & & & & \\
\hline
\end{tabular}

FBS1-at one month of treatment, FBS3-at end of 12 months of treatment

\section{DISCUSSION}

Diabetes mellitus (DM) is an important public health problem in developing countries. ${ }^{6}$ The important threats to health and life that beset the person with diabetes are cardiovascular disease (CVD), cerebrovascular and peripheral vascular disease. ${ }^{7}$ The associated co-morbid conditions seen with diabetes mellitus are hypertension, dyslipidaemia, neuropathy, nephropathy and retinopathy. About $20-60 \%$ of diabetic patients are associated with hypertension as a co morbid condition. ${ }^{8}$ In present study, most of the patients were stabilized with a combination of triple drug combination including pioglitazone, metformin and glimepiride. These are combination of sulfonylurea (an insulin secretogogue) and insulin sensitizers (biguanide and thiazolidinedione both acting by different mechanisms). Similar results were observed in Panikar et al studies. ${ }^{9}$ About $27.3 \%$ of patients in our study had combination of glibenclamide and metformin as second most commonly used medication with better glycemic control. Kannan et al studies had the similar combination as most common prescribing pattern in tertiary care centre in Tamilnadu. ${ }^{10}$

Poor Medication adherence (PMA) is a commonly seen in long term non-communicable diseases such as diabetes. PMA is associated with escalation of treatment costs and clinical outcomes. ${ }^{11}$ Patient having depression, blind beliefs and medicinal costs were attributed to PMA in Polonsky studies. ${ }^{11}$ In our study the main factors which led to poor adherence were unknown reasons, follow-up irregularity, noncompliance for adverse reactions and medication ignorance. Polypharmacy and addiction to smoking and alcohol were also minor factors which influenced the outcome of our study. The unknown reasons may be depression or distress altering the patient's perception of diabetes and their willingness to actively manage their own health. ${ }^{11}$ Future research on a larger patient population is warranted to evaluate existing patterns of therapy for sound practice and quality of care.

\section{ACKNOWLEDGEMENTS}

Authors would like to acknowledge the Karuna trust, Davangere for their support in obtaining the patient data.

Funding: No funding sources

Conflict of interest: None declared

Ethical approval: The study was approved by the Institutional Ethics Committee

\section{REFERENCES}

1. Khan GH, Aqil M, Pillai KK, Ahmad MA, Kapur P, Ain MR et al. Therapeutic adherence: A prospective drug utilization study of oral hypoglycemic in patients with type 2 diabetes mellitus. Asian J Trop Dis. 2014;4:347-52.

2. Sivasankari V, Manivannan E, Priyadarshini PS. Drug utilization pattern of anti-diabetic drugs in a rural area of Tamilnadu, South India- a prospective, 
observational study. Int J Pharm Bio Sci. 2013;4:514 19.

3. Kaveeshwar SA, Cornwall J. The current state of diabetes mellitus in India. AMJ. 2014;7:45-8.

4. Gaikwad A, Kanitkar S, Kalian M, Tamakuwala K, Agarwal R, Bhimavarapa B. Prevalence of type 2 diabetes mellitus in candidates contesting for municipal corporation elections in an urban industrialized town. Indian J Basic Appl Med Res. 2014;3:412-18.

5. Sajith M, Pankaj M, Pawar A, Modi A, Sumariya R. Medication adherence to antidiabetic therapy in patients with type 2 diabetes mellitus. Int J Pharm Pharm Sci. 2014;6:564-70.

6. World Health Organization. Global Report on Diabetes. Isbn [Internet]. 2016:978-80 Available from:

http://www.who.int/about/licensing/nnhttp://apps.who .int/iris/bitstream

/10665/ 204871/1/9789241565257_eng.pdf

7. Cdc. A Public Health Action Plan to Prevent Heart Disease and Stroke. 2010; Available from: http://www.cdc.gov/dhdsp/action_plan/pdfs/action_pl an_full.pdf
8. Matheus ASDM, Tannus LRM, Cobas RA, Palma CCS, Negrato CA, Gomes MDB. Impact of diabetes on cardiovascular disease: An update. Int J Hypertens. 2013;2013.

9. Panikar V, Chandalia HB, Joshi SR, Fafadia A, Santvana C. Beneficial effects of triple drug combination of pioglitazone with glibenclamide and metformin in type 2 diabetes mellitus patients on insulin therapy. $\mathrm{J}$ Assoc Physicians India. 2003;51:1061-4.

10. Kannan, Arshad, Kumar S. A study on drug utilization of oral hypoglycemic agents in type-2 diabetic patients. Asian J Pharm Clin Res. 2011;4(4):60-4.

11. Polonsky WH. Poor medication adherence in diabetes: What's the problem? J Diabetes. 2015;7:777-8.

Cite this article as: Raghu PMS, Patil D, Vishwanath BM, Shankar AS, Patil UN, Holyachi S. Pattern of drug utilization and factors influencing long term blood sugar control among diabetics in a tertiary care hospital- an observational study. Int J Basic Clin Pharmacol 2017;6:1171-4. 